\title{
Los sectores medios ante la era neoliberal: Transformaciones y contradicciones del desarrollo en Chile*
}

\author{
$\square \square$ \\ NIC OLÁS AN GELCOS, PABLO PÉREZ Y CAMILO SÉM BLER \\ Licenciadosen Sociología de la U niversidad de Chile
}

\begin{abstract}
::: RESU MEN
El presente artículo reflexiona sobre las condiciones de posibilidad que presentan los sectores medios para ejercer un rol activo en el modelo de desarrollo vigente en $\mathrm{C}$ hile, tal como tienden a ser presentadose interpelados discursivamente desde la esfera política. Para ello, en primer lugar, se examina la reconfiguración de las relaciones de poder durante las últimas décadas y la consiguiente articulación de un nuevo modelo societal. A partir de esto, se analizan los cambios en la estructura ocupacional y los mecanismos de integración social en los sectores medios, vislumbrando tanto sus bases constitutivas como sus tejidos normativos. Las consideraciones finales reflexionan sobre las tensiones entre dichos cambios y las interpelaciones discursivas que se dirigen hacia los sectores medios en la actualidad.
\end{abstract}

PA LA BR AS CLAVES: sectores medios, modelo de desarrollo, estratificación

\section{::: ABST R ACT}

Thisarticle reflects on the conditions of possibility that present the middle sectors to exert an active role in the current mode of development in $\mathrm{C}$ hile, as they are discursively presented and questioned from the political sphere. First, we examine the reconfiguration of the power relations during the past decades and the resulting articulation of a new societal model. Based on this, the changes in the occupational structure and the social integration mechanisms in the middle sectors are analyzed, glimpsing both their constitutive basis and their normative fabric. Finally we consider the tensions between those changes and the discursive interpellations directed to the middle sectors nowadays.

K EY W O R D S: middle sectors, mode of development, stratification 


\section{Introducción}

El presente artículo intentará desarrollar una reflexión desde la sociología hacia el carácter actual que presentan los sectores medios. M ás que una caracterización descriptiva en términos de estructura ocupacional se intentará formular una reflexión en torno a las condiciones de posibilidad que estos sectores presentan para ejercer un rol activo en la sociedad chilena actual. Este rol activo estaría definido por la capacidad que pudieran tener de desarrollar un proyecto histórico, que diera una direccionalidad clara al modelo de desarroIlo actual.

En este sentido, los sectores medios constituirían actualmente el núcleo de una paradoja, en la medida que, por un lado, son los sectores que cargan en sus espaldas buena parte de los costos del modelo de desarrollo y, por otro, constituyen los sectores privilegiados hacia los cuales se orienta el discurso político, interpelándolos a constituirse como las bases sociales que sustenten un nuevo y renovado pacto social en $\mathrm{C}$ hile.

Esta paradoja se extiende más allá del ámbito indicado para dejar lugar a la contradicción entre su interpelación discursiva como sectores homogéneos claramente constituidos, a la vez que su conformación «real» nos muestra una alta heterogeneidad estructural en su composición social y, por lo mismo, una diversidad de identidades culturales sin un referente único; referente que, como veremos, estaba constituido por el Estado entre los años 1930 y 1973 del pasado siglo.

Así, el artículo intentará caracterizar el conjunto de reformas estructurales y políticas acaecidas durante los años ochenta, para preguntarse acerca de la reconfiguración de las relaciones de poder en Chile y la forma que adopta el nuevo patrón de acumulación, basado en la apertura económica hacia capitales trasnacionales. En un segundo momento, caracterizaremos los principales cambios que se evidencian en la estructura ocupacional, para indagar en las bases objetivas en que se constituyen los sectores medios. Enseguida, analizaremos los cambios que se producen en las principales formas de integración social, hacia un marcado auge del consumo, reflexionando sobre la recomposición de tejidos normativos que esta forma de integración simbólica posibilita o niega.

Por último, quisiéramos aclarar una distinción conceptual que orientará este artículo, a saber: la distinción entre sectores medios y clase media. En general, en este artículo, utilizaremos el concepto de sectores medios para desligarlo de una carga teórica que en la realidad no podemos constatar como evidente. Pareciera ser objetivo de un trabajo de investigación el definir con precisión si los sectores medios constituyen clases, estratos, estamentos, etc.; objetivo que se aleja de nuestras pretensiones. Por lo mismo, si utilizamos en al gunos pasajes la idea de clase media sólo lo hacemos dando cuenta de la caracterización con la que el discurso político los interpela, lejano a lo que entendemos por clase, es decir, un grupo social organizado con una base económica y social común, que porta un proyecto histórico y lucha por volverlo hegemónico. 


\section{R eordenamientos sociopolíticos y transformaciones estructurales recientes. Elementos para una caracterización de Chile como modelo societal neoliberal.}

El diagnóstico y la reflexión sobre las bases constitutivas y los mecanismos de integración social de los actuales sectores medios, exige, en primer lugar, un intento de caracterización de las principales tendencias y rasgos que configuran las estructuras y dinámicas sociales hoy en C hile. Particularmente, se trata de precisar algunos elementos para la comprensión del contexto social en el cual se constituyen y desenvuelven los sectores medios, sobre todo apuntando a los reordenamientos sociopolíticos y las transformaciones estructurales que están en la base de la articulación histórica de un nuevo modelo societal en Chile desde la construcción hegemónica del neoliberalismo.

En términos generales, las tranforformaciones y ajustes estructurales que, principal mente, a partir de la década de los ochenta comienzan a implementarse en Chile al amparo de los procesos de modernización neoliberal, no sólo redefinen la organización productiva y las relaciones laborales características del modelo industrializador, sino que también desestructuran las relaciones clásicas entre la sociedad civil y el Estado, o en términos más amplios, entre la constitución y orientación de los actores sociales y la institucionalidad política. En otras palabras, las transformaciones impulsadas desde las recomendaciones neoliberales no sólo impactan en la organización económica de la sociedad, sino que provocan, en términos de Garretón, una desarticulación de la matriz nacional-popular característica del período industrializador, vale decir, una redefinición de las relaciones entre el Estado, el sistema de representación política y las bases socioeconómicas y culturales a partir de las cuales se constituyen los actores sociales.

Es por todo esto, entonces, que podemos hablar de la articulación histórica de un nuevo tipo societal en Chile, desde la construcción hegemónica del neoliberalismo y la racionalidad particular que éste imprime a las estructuras, dinámicas y comportamientos sociales, y que logra prolongarse $-\mathrm{y}$ en ciertos aspectos esenciales profundizarse- más allá de su momento fundacional signado por la dictadura militar. En este sentido, intentaremoscaracterizar el neoliberalismo como un particular estilo de desarrollo sustentado en una serie de reordenamientos sociopolíticos - entendidos como alteraciones en las relaciones de poder entre sujetos y fuerzas sociales - que suceden a la crisis del Estado de compromiso y el modelo industrializador y que, desde ahí, se va instalando, a partir de procesos de modernización que modifican tanto los mecanismos sistémicos (mercado, aparato político-administrativo, estructura ocupacional, etc.) como los anclajes normativos de la sociedad chilena.

Como es sabido, durante el período histórico englobado bajo el modelo industrializador sustitutivo de importaciones (ISI) es posible apreciar que los actores sociales fundamentales se constituían en torno a la esfera del trabajo y, en base a ello, articulaban y proyectaban sus orientaciones normativas hacia la institucionalidad política, mediante formas de acción colectivas (sindicatos, movi- 
mientos sociales) y el sistema de representación (Partidos Políticos). D ichos actores, además, se articulaban en torno al movimiento social central (nacionalpopular) y el impulso del desarrollismo, encontrando en el Estado su principal referente de acción y el lugar de resolución de los conflictos generados por las relaciones de dominación (véase Garretón, 1997).

A hora bien, con el estancamiento estructural del proyecto industrializador y la crisis mundial de 1974 - y el consiguiente incremento de la deuda externa en los países dependientes- se cerrará un ciclo histórico de acumulación y modernización capitalista en la región, planteándose el desafío de impulsar un nuevo ciclo redefiniendo el estilo de desarrollo, lo que abre el paso a una serie de transformaciones estructurales de la sociedad chilena. Sin pretender entrar a detallar una historia ya conocida, dicho estilo de desar rollo comenzaráa articularse a partir de los dictámenes del neoliberalismo, sobre todo sustentados en el diagnóstico de que, debido al estancamiento del consumo interno y la crisis fiscal del Estado benefactor, debe ser la inversión privada quien asuma estructuralmente el dinamismo del nuevo ciclo de acumulación. ${ }^{2}$

A demás de lo mencionado, otro aspecto esencial que debe considerarse para la comprensión de las tranformaciones que van articulando el actual modelo societal en $\mathrm{C}$ hile remite al salto en la base técnica del capital que comienza a producirse a nivel mundial a partir de los 60 . En efecto, durante aquellos años se asiste a un desplazamiento global de la centralidad de los procesos productivos anclados en la industria hacia otras esferas y espacios sociales, sobre todo aquellos estructurados en torno al sector servicios y la economía financiera. Es precisamente en aquel entonces cuando se comienza a plantear la idea de una sociedad postindustrial, en donde acorde al desplazamiento productivo se reorganizarían los mecanismos identitarios y los ejes de conflictividad social y, con ello, las consiguientes pautas de orientación y comportamiento de los grupos sociales. Para el caso de C hile - y en general para A mérica Latina- tenemos, por tanto, que el estancamiento tecnológico del modelo industrializador se entronca con la transformación planetaria de la organización del capital, lo que está en la base del proceso de constitución de un modelo societal neoliberal, en donde a partir de una serie de profundas y variadas transformaciones estructurales se van redefiniendo tanto las bases constitutivas como los mecanismos de integración de los actores sociales.

Sin embargo, es fundamental destacar - sobre todo al intentar analizar la constitución y los patrones de comportamiento de determinados grupos sociales, en este caso, los sectores medios- que si bien la crisis presenta un marcado carácter estructural, su agudización y su salida, a través de la serie de reformas y ajustes neoliberales, es imposible de entender sin el aspecto sociopolítico que implica la desarticulación de la alianza de clases desarrollista y la conformación, planteado en términos de G ramsci, de un nuevo bloque histórico hegemónico

${ }^{2}$ Esto considerando la demanda interna como la articulación entre inversión privada, consumo y gasto público, en donde, en éste momento histórico leído desde el monetarismo, sólo la primera puede redinamizar la demanda y abrir un nuevo ciclo de acumulación. 
articulado, so bre todo, en torno a los sectores ligados a la fracción financiera del capital, principalmente transnacional, y subordinadamente, local. ${ }^{3}$

Se trata, en el fondo, del quiebre político del pacto 0 alianza social que sustenta al Estado de C ompromiso, lo que agudiza la crisis sistémica del modelo industrializador mediante la articulación de una crisissocial, en donde se reordenan las relaciones de poder entre los sujetos y fuerzas sociales, dando lugar a la emergencia de nuevas posiciones dominantes. ${ }^{4}$ En estos términos, entonces, la conformación de una sociedad neoliberal en $C$ hile responde a la capacidad del emergente bloque histórico de asumir la crisis y darle una salida por medio de transformaciones estructurales que van instalando y articulando un nuevo modelo societal.

D esde aquí, el cambio societal experimentando en C hile durante las últimas décadas puede ser entendido no sólo como «un proceso acumulativo en el cual se agregan nuevas variables que se incorporan a la configuración estructural, [sino que] implica fundamentalmente un proceso de relaciones entre los grupos, fuerzas y clases sociales a través del cual algunos de ellos intentan imponer al conjunto de la sociedad el tipo de dominación que les es propio» (C ardoso y Faletto, 2003: 13). En suma, los procesos de modernización neoliberal representan la implementación sistémica y normativa del proyecto político de un bloque histórico que se representa sobre la totalidad del orden social, logrando instalar como hegemónicas sus orientaciones prácticas (estructurales y normativas) particulares.

De esta manera, si bien el proceso de implantación del nuevo tipo societal arranca de la posibilidad que le otorga el Golpe M ilitar como ruptura política final de la alianza desarrollista, las transformaciones estructurales que instalan la lógica de modernización neoliberal son posteriores, en la medida en que son expresión de un paulatino reordenamiento sociopolítico de las relaciones de poder entre los actores y fuerzas sociales. D e hecho, es posible identificar una etapa que va - aproximadamente- entre 1973 y 1975, en donde se van resolviendo las tensiones internas a los sectores golpistas, que precisamente guardaban relación con la orientación que debía asumir el modelo de desarrollo en Chile, ${ }^{6}$ las cuales finalmente son resueltas a favor del nuevo bloque histórico que va emergiendo como hegemónico e instalando las transformaciones neoliberales profundas que sientan una nueva lógica de modernización social.

En 1975, entonces, se inaugura la etapa fundacional de la dictadura que engloba

${ }^{3} \mathrm{C}$ abe recordar que, desde $\mathrm{G}$ ramsci, puede considerarse que el bloque histórico no sólo proyecta hegemonía sobre la sociedad, sino que también en su interior - como alianza de clases y fracciones sociales - se construyen relaciones hegemónicas, es decir, posiciones directivas de determinados grupos sociales sobre otros.

${ }^{4}$ Parala distinción entre crisissistémicay crisis social, véase H abermas(1998).

${ }^{6} \mathrm{~N}$ os referimos a las disputas entre las visiones corporativistas y las neoliberal es que conviven, en un primer momento, al interior de los sectores golpistas, y que son resueltas a favor de los últimos fundamentalmente a partir de 1975 y de la influencia de los economistas de Chicago. 
una serie de cambios profundos que tienen por objetivo principal desarticular las condiciones estructurales y políticas que hacían posible el modelo de desarrollo anterior, so bre todo las que guardaban relación con la injerencia del Estado en los procesos de generación y distribución del producto social, lo cual además es acompañado de las políticas de represión tendientes a fragmentar a los actores clásicos de la matriz nacional-popular. Es decir, se trata de crear las condiciones económicas, sociales y políticas que posibiliten la implantación del nuevo modelo societal.

En este primer momento se redefinen, profundamente, las bases objetivas a partir de los cuales se constituían los actores sociales en el período desarrollista, sobre todo en relación a la esfera del trabajo y la estructura ocupacional, particularmente mediante una alteración de la organización productiva y sus relaciones laborales características. C onviene precisar, que si bien apuntaremos las principales transformaciones que en esta esfera representan las reformas y ajustes neoliberales, nos interesa enfatizar la medida en que debido a su profundidad reestructuradora, éstas implican tendencias o lógicas que se prolongan más allá del momento fundacional y, por ello, son importantes para establecer el contexto social actual de constitución de los sectores medios. Dicho en términos más concretos, nos interesa más bien caracterizar la lógica o racionalidad que instala la modernización neoliberal sobre las estructuras y dinámicas sociales, y no tanto sus hitos o momentos de reforma particulares.

Así, en primer lugar, es posible identificar que como producto de uno de los ejes del reordenamiento sociopolítico que desencadena las transformaciones, se ha producido una redefinición de los actores que lideran la inversión y la acumulación, que va desde el rol empresarial del Estado durante el período industrializador - en la medida en que organizaba la producción estratégicamente, otorgaba puestos de trabajo y satisfacía determinados niveles de consumo- hacia la preponderancia, como ya se apuntó, de la inversión privada anclada en torno a la especulación financiera y los servicios. D e esta manera, por ejemplo, en términos del producto interno, hacia 1965 el Estado participaba en el $3 \%$ de la producción manufacturera nacional, lo cual se incrementa al $40 \%$ para el año 1973, para volver drásticamente al 3\% en 1998; similar a lo que acontece en el área estratégica de la minería, en donde se pasa de un control estatal del $85 \%$ de la producción (1973) a una participación del 45\% hacia finales de los noventa. ${ }^{7}$

Ahora bien, esta reorganización productiva también va acompañada de una modificación profunda de los mecanismos encargados de asignar recursos para la inversión, vale decir, del sistema financiero. En este caso, se trata de la liberalización de dichos mecanismos - bajo la premisa monetarista que enfatiza la necesidad de despojarlo de todas las trabas posibles, para así orientar la inversión a las ramas más eficientes y rentables, dinamizando con ello el crecimiento- , Io cual ha introducido una tensión constante entre la asignación de recursos y las

${ }^{7}$ D atos extraídos de $\mathrm{H}$ achete (2000: 115). 
necesidades de empleo y desarrollo local, toda vez que se tiende a privilegiar las ramas que aseguren solvencia y altas tasas de retorno (tasas de interés). ${ }^{8}$

Sin embargo, no sólo se ha producido una transformación técnica de los procesos productivos y una liberalización del sistema financiero, sino que también una profunda redefinición de las relaciones laborales 0, dicho más ampliamente, la nueva racionalidad que desprenden los procesos de modernización neoliberal también ha impactado en la organización del trabajo social. A grandes rasgos, en este ámbito se ha incorporado una tendencia creciente a la fragmentación del proceso de trabajo, con la consiguiente precarización del empleo, fundamentalmente bajo las formas de la externalización de funciones y la terciarización, en donde, por ejemplo, se puede apreciar que en 1987 el 14\% de los puestos de trabajo correspondía a subempleos, vale decir, trabajos con salarios inferiores al mínimo o jornadas laborales por debajo de las 35 horas semanales, lo cual hacia 1996 se incrementa hasta el 17\% (M ontero y M orris, 2001).

Esta nueva racionalidad que fragmenta el proceso de trabajo se liga estrechamente a las formas en que se ha reorganizado la propiedad de la producción, la cual se caracteriza por presentar una organización horizontal ligada en un nivel superior a la propiedad de un capital hegemónico (la figura de los conocidos holdings o conglomerados empresariales). ${ }^{10}$ Lo fundamental de advertir en este punto, es que la flexibilización laboral, la subcontratación, la polivalencia funcional, entre otros aspectos que dan cuenta de la fragmentación del proceso de trabajo, se desprenden de la necesidad estructural que plantea el modo (horizontal) en que se organiza la producción bajo la lógica de la modernización neoliberal, lo cual además impacta en la dificultad sostenida de articular - desde la esfera del trabajo- vínculos sociales estables que posibiliten la constitución de actores que le otorguen un sustrato normativo sólido al orden y sus dinámicas imperantes. Es justamente en los sectores medios, clásicamente estructurados en torno al trabajo asalariado, donde podemos encontrar una de las categorías sociales donde mayormente ha impactado la reorganización de las relaciones laborales.

Finalmente, se puede diagnosticar que al amparo de las reformas neoliberales se ha producido una reorientación de los procesos de distribución del producto social, en donde ésta - la distribución - ha pasado de ser una necesidad para asegurar el dinamismo y continuidad del modelo industrializador, a ser un límite y obstáculo para la nueva racionalidad que promueve la modernización neoliberal. En efecto, para el proyecto desarrollista la distribución aparecía como un criterio esencial para el desenvolvimiento dinámico de un mercado interno capaz de asegurar el consumo necesario que necesitaba la producción nacional,

${ }^{8}$ El ejemplo paradigmático de esta tensión es el caso de laspequeñas y medianas empresas, las cuales al no dar seguridad al sistema financiero encuentran dificultades en el acceso al crédito, lo cual contrasta con su situación de ser el sector productivo más intensivo en la gestación de empleos.

${ }^{10}$ Para una mayor revisión e ilustración de la idea de una organización horizontal de las actividades productivas bajo la propiedad de un capital hegemónico, véase Fazio (2005). 
a partir de lo cual se entienden las políticas redistributivas promovidas desde la injerencia estatal (ya sea las que actuaban de forma directa - modificando la estructura de la renta- 0 indirectamente vía servicios públicos que posibilitaban un incremento de la capacidad adquisitiva disponible).

Por el contrario, para la lógica instalada por las reformas neoliberales, la redistribución planificada aparece como un problema, como un freno para la racionalidad sistémica, toda vez que, a partir de la primacía que ha asumido el comercio exterior, la producción se orienta y define principalmente de acuerdo al mercado global y no en relación a las necesidades locales o capacidades internas. Por lo mismo, si la competencia se orienta primordialmente hacia el merca do exterior, aparece limitada y orientada de acuerdo a los precios que ahí se definen, por lo cual ante la imposibilidad estructural de un salto tecnológico importante, el incremento de la ganancia se articula especialmente en torno a la presión constante sobre la fuerza de trabajo, vale decir, mediante la tendencia a la precarización de las fuentes de empleo y las relaciones laborales.

En suma, podemos señalar que, a partir de 1975, se comienzan a instalar una serie de transformaciones estructurales que van articulando, dicho en términos clásicos, un nuevo patrón de acumulación en $C$ hile, es decir, un nuevo modo histórico en que se produce la valorización y acumulación del capital. Son estas transformaciones, entonces, las que minan las bases objetivas de constitución de los actores clásicos - como obreros y sectores medios - al mismo tiempo que constituyen la plataforma desde la cual van emergiendo nuevos sujetos dominantes, como ya hemos señalado, especialmente aquellos articulados en torno al capital financiero. Por ello, se trata en el fondo de una redefinición sociopolítica de los actores o fuerzas sociales que conducen y dan dinamismo al modelo de desarrollo, a partir de lo cual se modifica la organización productiva, los mecanismos de inversión y las relaciones laborales, desplegando con ello el momento económico-estructural de la construcción hegemónica del nuevo bloque histórico neoliberal.

Sin embargo, con la crisis económica de 1982/83, se comienzan a traslucir las consecuencias sociales del crecimiento y dinamismo del modelo articulado a partir de las reformas y ajustes neoliberales, impulsando, como se recordará, una serie de movilizaciones y jornadas de protesta de amplios sectores sociales perjudicados por las transformaciones recientes. $\mathrm{N}$ o obstante, las condiciones particulares en que los actores políticos van gestando el proceso de transición a la democracia permiten la instalación de una disociación creciente entre el malestar social frente al modelo económico y el cuestionamiento al régimen político, de modo tal que los sectores dominantes centran sus esfuerzos en la reapertura del espacio democrático formal, a la vez que articulan un consenso esencial sobre la legitimidad del estilo de desarrollo vigente(véase $R$ uiz, 1993). C on ello, el nuevo bloque histórico logra proyectarse sobre la conducción de las dinámicas políticas, diluyendo a la vez el malestar hacia el modelo económico bajo la premisa - instalada en el imaginario público - de que sus perjuicios (la «deuda social») son una tarea a enfrentar en la paulatina consolidación de la democracia, y no una consecuencia inherente a la racionalidad estructurante del modelo de 
desarrollo. La nueva democracia chilena, desde ahí, asumirá un notorio énfasis en la gobernabilidad, vale decir, en el control del malestar social y la posibilidad de conflictividades que pudieran poner en tela de juicio a la democratización política.

A hora bien, este proceso histórico de construcción hegemónica - que, como hemos apuntado, se abre con el inicio de las reformas y ajustes estructurales para luego pasar por el proceso de transición política- al mismo tiempo va encontrando una consolidación y legitimidad importante mediante una redefinición profunda de las estructuras normativas y las representaciones simbólicas de la sociedad chilena. En este caso, entonces, se trataría de la articulación del momento ético-moral de la hegemonía, desde el cual se reorganizan lasfuentesidentitarias, los mecanismos de integración social y representación simbólica, entre otros aspectos sustanciales en la constitución de los actores y grupos sociales. ${ }^{12}$

Particularmente, este momento histórico va ligado a la expansión creciente de los mecanismos mercantiles sobre los plexos normativos y las constelaciones simbólicas, lo cual se inaugura, aproximadamente, en los años inmediatamente posteriores a la crisis del 82/3, plasmándose en una nueva etapa de cambios, conocida como los ajustes de segunda generación, que extienden las privatizaciones y lógica del mercado a los distintos ámbitos sociales, incluyendo, en algunos casos, garantías institucional es- jurídicas. ${ }^{13}$

Se trata, entonces, de que el mercado no sólo se asume como un mecanismo de coordinación sistémica, sino que se instala, crecientemente, en una diversidad de espacios o contextos en los cuales actúa redefiniendo las pautas normativas, identitarias y los consiguientes comportamientos de los diversos sectores sociales.

D e esta manera, si en el período industrializador el Estado - al mismo tiempo que, como vimos, organizaba la producción y la distribución del producto social- aparecía como el referente simbólico fundamental de la acción colectiva, o sea, como el centro de toma de decisiones que articulaba la sociedad polis menguando los conflictos entre las particularidades, mediante la formación de una voluntad política anclada en el desarrollismo, siendo, por lo mismo, el principal eje constitutivo de las identidades sociales. Se trataba, en efecto, de la construcción de una identidad estado-nación, vale decir, el proceso de constituirse como sujeto y participar de la polis en la medida en que opera el reconocimiento estatal de la condición de ciudadanía.

A hora, con la lógica que ha instalado la modernización neoliberal, la acción colectiva ha tendido a ser desplazada por la racionalidad tecnocrática, sobre

12 Para Gramsci, precisamente, la construcción de hegemonía por parte de un bloque histórico implica siempre tanto un control económico como un momento cultural-político. «Si la hegemonía es ético-político no puede dejar de ser también económica, no puede menos que estar basada en la función decisiva que el grupo dirigente ejerce en el núcleo rector de la actividad económica» (véase G ramsci, 1971: 55).

13 Por ejemplo, con la implementación de la Ley 0 rgánica C onstitucional de Enseñanza, que termina de desarticular la universidad nacional propia del desarrollismo, instalando en su lugar mecanismos de autofinanciamiento y abriendo las instancias educativas al mercado. 
todo bajo la consideración - fuertemente instalada en el sentido común desde el discurso hegemónico- que las estructuras sistémicas vigentes llevadas al extremo de su funcionalidad posibilitarían el bienestar social, frente a lo cual la acción social debe acoplarse a ellas, mediante el desarrollo de estrategias individuales de maximización de beneficios. El mercado, en suma, aparece como el mecanismo capaz de asignar el óptimo social y, por ende, el consumo como la práctica racional por excelencia, lo cual ha acarreado una reorganización profunda de los mecanismos de integración social, particularmente con profundas implicancias, como veremos, para el caso de los sectores medios.

En este sentido, a los, tantas veces mencionados, procesos de desafección hacia la democracia o respecto a las instancias de participación y representación política formal, les subyace una profunda reorganización de las representaciones, identidades y valores que orientan la acción social. En efecto, la primacía del mercado como eje estructurador de la dinámica social, ha llevado a una fragmentación de los vínculosy relaciones, en donde la acción aparece crecientemente replegada sobre sí misma, privatizada, dejando de aparecer en lo público mediante la articulación de intereses colectivos. Los marcos institucionales, en este contexto, son progresivamente vaciados del sentido normativo que le imprimen los actores desde sus orientaciones y, por ello, tienden a desplegarse arrastrando una creciente sensación de contingencia, como pareciesen graficarlo las expresiones de malestar e inseguridad que han acompañado a los procesos de modernización en C hile (véase PN U D, 1998).

En suma, asistimos a la articulación de un nuevo modelo societal desde los procesos de modernización neoliberal, en donde las bases objetivas de constitución de los actores sociales clásicos aparecen minadas, y sus referentes de integración y conformación de identidades son desestructurados. Es en este contexto societal, entonces, que intentaremos diagnosticar y reflexionar en torno a la situación de los sectores medios.

\section{Cambios en la estructura ocupacional. Un análisis de los sectores medios a partir de la transformada esfera del trabajo}

Sin lugar a dudas, las transformaciones acaecidas durante la dictadura militar reseñadas anteriormente trajeron consigo muchos cambios en la estructura social existente hasta ese entonces, configurada a partir del anterior modelo de desarrollo basado en la industrialización sustitutiva de importaciones. En este sentido, son de especial importancia los cambios acaecidos en la estructura ocupacional, ya que ésta es una de las dimensiones que afecta, en gran medida - aunque, por supuesto, no de modo exclusivo - la constitución de las clases sociales.

De aquí, pues, que sea de suma importancia considerar a esta dimensión como una de las fundamentales para comprender la naturaleza que tienen los sectores medios en el $\mathrm{C}$ hile neoliberal, considerando que a partir de las distinciones procedentes de la esfera del trabajo se puede dar cuenta, en cierto sentido - aunque no categóricamente- de la desigual distribución de oportunidades sociales, de las desiguales orientaciones culturales, políticas, etc. 
Para partir, se puede señalar que en los primeros años de las transformaciones neoliberales, $C$ hile experimentó una serie de fenómenos que determinaron que la estructura ocupacional se viera caracterizada por varios factores propios de esa época. Entre los más importantes se puede mencionar el precario crecimiento de la ocupación en relación al aumento necesario para absorber la creciente fuerza de trabajo; la acelerada disminución de la población activa localizada en la agricultura y el gran aumento de la localizada en el sector terciario; la progresiva reducción del empleo público en el total de la población ocupada (que hasta finales de los 80 no fue suficientemente acompañada de un aumento paralelo del empleo privado), etc.

Este último fenómeno se torna especialmente relevante cuando se quiere estudiar a los sectores típicamente denominados como «clase media», en la medida en que en lo referido al ámbito laboral, es posible apreciar que desde la década del 70 ésta se fue diferenciando cada vez más entre sus estratos asalariados (del sector público y privado) e independientes.

En efecto, entre las múltiples transformaciones estructurales que definieron la nueva conformación de los sectores medios se puede señalar, como uno de los puntos fundamentales, su desligamiento del aparato estatal como principal fuente generadora de empleos. Esto se tradujo, luego de la retirada del aparato estatal de su rol modernizador, en que las «clases medias» perdieran una importante fuente de empleo.

Lo anterior queda de manifiesto en cifras que nos muestran que hasta 1973 el empleo público experimentó un crecimiento progresivo que se revirtió radicalmente con la llegada de la dictadura militar, llegando a reducirse desde esa época hasta 1978 en casi 100 mil personas. Si se considera además lo que este tipo de empleo debió haberse expandido, de haberse mantenido en ese lapso la tendencia relativamente moderada de la década del sesenta, la reducción debe estimarse en 193 mil empleos (M artínez y T ironi, 1985: 90).15

Se debe señalar en este contexto que el crecimiento del empleo público hasta antes de 1973 no respondió al requerimiento de burocracia para labores administrativas, sino más bien al requerimiento de personal destinado a la prestación de servicios sociales llevados a cabo por el Estado - tales como educación y salud- y al fomento y ejecución directa de actividades productivas. Precisamente, estas labores de fomento fueron las que presentaron la mayor contracción entre 1973 y 1978 (de aproximadamente -19,18\%) (M artínez y Tironi, 1985: 93).

A hora bien, esta reducción del Estado no significó la disminución cuantita-

${ }^{15}$ C omo dato metodológico, se debe señalar que M artínez y Tironi realizan un análisis empírico de las consecuencias que tuvieron las tran forormaciones estructurales en las clases medias a partir de una matriz de análisis compuesta de 4 ejes de interpretación y seguimiento: 1) El papel del Estado (y del sector privado) en la constitución de la clase media; 2) la evolución de la clase media asalariada e independiente; 3) la evolución de los ingresos de los gruposmedios; y por último, 4) la función del consumo como proveedor de status de la clase media. 
tiva de los sectores medios bajo la forma de proletarización o marginalización, sino que más bien implicó su traslado a distintas actividades propias del ámbito privado. En efecto, más del 70\% del total de este sector continuó en 1980 ubicado en el segmento asalariado, disminuyendo eso sí el estrato de los administrativos, y aumentando los estratos vinculados al comercio y a los servicios, esferas en las cuales se apreció una fuerte heterogeneidad de ingresos entre las distintas jerarquías profesionales.

El sector financiero es también otro fragmento ocupacional donde se expandieron los sectores medios hacia finales de los 70. Así pues, con su privatización este sector creció extraordinariamente, lo que trajo consigo un fuerte incremento del empleo. Ejemplo de ello es que «en 1970 éste [sector ocupacional] estaba compuesto por 45.1 mil personas, que representaban el 1,7\% de la fuerza de trabajo del país; [mientras que] en 1981 se ocupaban en él 116,9 mil personas, el 3,6\% de la fuerza de trabajo» (M artínez y Tironi, 1985: 103). U na de las características del empleo en este sector es la gran heterogeneidad de los ingresos del personal, en la medida en que responden a una jerarquizada estratificación de las remuneraciones según cargo o función. Al mismo tiempo, las oportunidades de ascensos en los cargos parecen ser más elevadas que en todo tipo de ocupación burocrática.

O tra característica - quizá la más importante- de las clases medias en los años que van desde el inicio de la dictadura hasta comienzos de los 80 fue el relativo crecimiento, dentro de ellas, de las actividades independientes. En efecto, las cifras nos muestran que el sector independiente pasó de ser el $23 \%$ del total de la clase media en 1970, a ser el $25 \%$ en 1980 (véase cuadro 1). M ás específicamente se puede señalar que en esta década la expansión de la clase media independiente se explica fuertemente por un aumento extraordinario de la actividad independiente de transporte vehicular y, particularmente, de la explotación de vehículos (transportes de carga, taxis, etc.) (M artínez y T ironi, 1985: 107-9)..$^{18}$

Por cierto, esta independencia lograda por la clase media, más que ser el resultado de la interpelación ideológica a dicho grupo social por parte de un

Cuadro 1. Clase media independiente y asalariada $(1960,1970,1980)$

(Porcentajes)

\begin{tabular}{|l|l|l|l|}
\hline & 1960 & 1970 & 1980 \\
\hline Independiente & 28,7 & 23,2 & 24,7 \\
\hline Asalariada & 71,3 & 76,8 & 75,3 \\
\hline
\end{tabular}

Fuente: Universidad de Chile (Extraído de Martínez y Tironi, 1985: 107)

\footnotetext{
${ }_{18}$ Se debe señalar que la relevancia que tiene este fenómeno de desalarización sobre los sectores medios se aprecia en que, por ejemplo, si bien el aumento de la importancia relativa de las ocupaciones independientes es un fenómeno que se da en todos los estratos de la sociedad, dicho incremento fue notoriamente más pronunciado en los estratos medios que en los altosy los bajos.
} 
modelo de desarrollo en auge sustentado en las prácticas de «emprendimiento», es consecuencia de la cesantía que éste genera. En este sentido, el crecimiento de los sectores independientes hasta mediados de los 80 se explica en su gran mayoría por la presencia de grupos sociales que realizaron esta actividad como transitoria, en tanto que se vieron obligados a hacerlo, debido a la incapacidad de la estructura ocupacional de absorber la progresiva expansión de las actividades calificadas.

A hora bien, si se hace referencia a la evolución de los ingresos dentro de las clases medias, podemos señalar que en los estratos asalariados éstos disminuyen desde la década de los 60 hasta el año 80, mientras que en los sectores independientes se apreció un aumento de losingresos dentro del mencionado intervalo de años. Así, por ejemplo, en 1960 un 40,3\% de los sujetos de la clase media asalariada se encontraban dentro del nivel alto de ingreso (o sea, dentro del quintil más alto). Este hecho cambia en 1980, año en el cual un $35,1 \%$ de los sujetos de ese estrato se encontraban en ese nivel de ingreso; por su parte, en la clase media independiente se apreciaba un porcentaje de 33,6\% en 1960, y de $36,6 \%$ en 1980 respectivamente. Por ello, se puede afirmar en términos relativos que hasta los años 80 se apreció un empobrecimiento de la clase media asalariada y una relativa mejoría del sector independiente (véase cuadro 2).

A partir de las características recién mencionadas, podemos señalar que hasta principios de los 80, fenómenos tales como la privatización de los sectores medios, las desiguales distribuciones remunerativas en su interior y el crecimiento de los estratos independientes incrementaron de sobremanera la heterogeneidad de su composición social, hecho que redundó en la progresiva limitación de una acción colectiva llevada por la clase media en base a intereses generalizados, es decir, en base a demandas compartidas por ese sector en su totalidad.

Cuadro 2. La clase media según niveles de ingreso 1960-1980

\begin{tabular}{|l|c|c|c|c|}
\hline & & $\begin{array}{c}\text { Alto } \\
\text { (Quintil V) }\end{array}$ & $\begin{array}{c}\text { Medio } \\
\text { (Quintiles III y IV) }\end{array}$ & $\begin{array}{c}\text { Bajo } \\
\text { (Quintiles I y II) }\end{array}$ \\
\hline \multirow{2}{*}{ Clases medias } & 1960 & 38,4 & 47,1 & 14,6 \\
& 1970 & 36,2 & 48,4 & 15,4 \\
& 1980 & 35,5 & 50,0 & 14,6 \\
\hline Clase media & 1960 & 33,6 & 43,0 & 23,5 \\
independiente & 1970 & 34,3 & 43,1 & 22,6 \\
& 1980 & 36,6 & 48,6 & 14,8 \\
\hline Clase media & 1960 & 40,3 & 48,7 & 11,1 \\
asalariada & 1970 & 36,7 & 50,0 & 13,3 \\
& 1980 & 35,1 & 50,5 & 14,5 \\
\hline
\end{tabular}

Fuente: Universidad de Chile (Extraído de Martínez y Tironi, 1985: 112).

A sí pues, en base a esto, se fueron marcando las pautas que determinaron la progresiva reducción de la capacidad de acción política que tuvieron los sectores medios luego de 1973. Esta capacidad de acción política, si bien no era lo suficientemente clara en la época del Estado de compromiso - lo que se expresaba, por ejemplo, en que estos sectores se comportaran muchas veces como 
aliados de las clases populares, mientras que otras veces se situaran en posiciones más cercanas a las de las clases dominantes- , sí presentaba cierta homogeneidad en la medida en que se articulaba en torno a las «demandas mesocráticas» hechas al Estado por estos sectores.

Por el contrario, en tanto que sus componentes sociales se fueron individualizando cada vez más (con la proliferación de actividades independientes y con la aparición de nuevas estructuras ocupacionales menos rígidas que permitían, por ejemplo, que se incrementaran los procesos de asenso dentro de las empresas como resultado del «esfuerzo individual») y, en la medida en que se dejó de ver al Estado como el órgano referente de sus demandas sectoriales, se fueron asentando las bases para que estos sectores tuvieran una mínima capa cidad de acción en torno a intereses generales (los cuales se presentaban, de alguna manera u otra, con cierta claridad hasta inicios de los 70).

En base a esto, a partir de las características que configuraron a la «clase media» desde la llegada de la dictadura militar hasta los años 80, podemos señalar otras tantas que determinaron la forma que tomó este sector al llegar la década de los 90 . H ablando en términos generales, podemos afirmar que las principales transformaciones en materia de la estructura ocupacional acaecidas entre los 70 y la década de los 90 son la terciarización de la economía, la disminución de la clase obrera industrial y el aumento de la burocracia privada. A demás, tal como se apreció tendencialmente al llegar a 1980, la movilidad social que prima en este período es la de tipo individual, hecho que explica que los empleados obtengan empleos de salarios más altos que los sujetos pertenecientes, por ejemplo, a la clase obrera (véase León y M artínez, 2001).

Por otro lado, se puede apreciar que, desde el comienzo de la dictadura hasta la llegada de la democracia, se observó una tendencia de desestructuración de actores sociales de tipo clasista resultante de las transformaciones neoliberales, en la medida en que éstas descomponían las bases constitutivas de dicho tipo de actores. En efecto, y si nos centramos en datos referidos a los sectores medios, se puede apreciar por ejemplo que entre 1971 y 1995 hay un aumento persistente de los sectores medios asalariados, que de ser $18 \%$ del total de las categorías sociales (población económicamente activa) en 1971, pasaron al ser $29 \%$ en 2000 (véase cuadro 3). ${ }^{20}$

El crecimiento de los sectores asalariadosno es un hecho menor teniendo en consideración que, hasta mediados de los años 80 , se observaba una tendencia al aumento de los sectores medios independientes (específicamente en los estratos de comerciantes y vendedores) en desmedro de los sectores medios asalariados.

Estos sectores medios asalariados son los que progresivamente se reubicaron en el sector privado, hecho que constituyó un gran impacto sobre su orientación a la movilidad social, en tanto existen notables diferencias entre este sector

${ }^{20} \mathrm{~A}$ este respecto se debe señalar que, si bien este sector de asalariados fue el que experimentó un mayor crecimiento sobre todo luego de los 80, fue el sector de trabajadoresindependientes el que en su mayoría presentó un mayor nivel de ingresos, especialmente a partir de la década de los 90. 
Cuadro 3. Evolución de los sectores medios en relación a la población económicamente activa (porcentajes)

\begin{tabular}{|l|c|c|c|c|c|}
\hline & 1971 & 1980 & 1990 & 1995 & 2000 \\
\hline Sectores medios & 26,2 & 33,5 & 31,3 & 36,2 & 37,2 \\
\hline a) Independientes & 7,8 & 9,2 & 6,3 & 8,1 & 8,2 \\
\hline b) Asalariados & 18,4 & 24,3 & 25 & 28,1 & 29 \\
\hline
\end{tabular}

Fuente: Elaboración propia de los autores a partir de datos presentados por Torche y Wormald (2004).*

y el público en términos de su estructura interna. En efecto, es la flexibilidad lo que distingue al empleo privado de la rigidez propia del público, situación que, como se sabe, determina la capacidad que tengan los sujetos de ascender de posición dentro de la jerarquía de las funciones laborales 0 , en su defecto, de mantenerse estático dentro de una estructura rígida que privilegia la antigüedad de los funcionarios por sobre las «capacidades personales».

$R$ especto a los cambios en la distribución del ingreso de las distintas categorías sociales dentro del período que estudiamos, podemos señalar que en base al examen de la movilidad relativa de losingresos en las distintas categorías sociales se examinan tendencias tales como: i) el distanciamiento de la clase obrera de los sectores medios; ii) el mejoramiento más rápido de los ingresos laborales de las categorías de trabajadores independientes en comparación con las posiciones asalariadas; y, como consecuencia de ello, iii) el cambio en la composición social de la pobreza, medida ésta sobre la base de un umbral de ingreso o línea de pobreza (véase León y M artínez, 2001: 19).

A hora bien, si se especifican estas tendencias respecto a los sectores medios, se puede ver que, por ejemplo, el punto i) puede constatarse en vista de la distinta evolución de los porcentajes de obreros y sectores medios con ingresos bajos, medios-altos y altos entre 1971 y 1995. En efecto, mientras en las categorías de la clase obrera disminuyó casi a la mitad la fracción con ingresos mediosaltos (de 42 a 23\%), y se duplicó de 8 a 17\% la fracción perteneciente al grupo de ingresos más pobres (20\% de ingresos más bajos), los sectores medios mantuvieron sin grandes variaciones su participación en los distintos grupos de la distribución del ingreso (en 1995, 2/ 3 de los miembros de estos sectores medios continuaban formando parte del $40 \%$ de mayores ingresos, y sólo 1 de cada 20 integraba el quintil más pobre) (véase León y M artínez, 2001: 20; véase con especial atención el cuadro número 5 presentado por los autores).

Basándonos en tales datos, no es difícil concluir que en el transcurso de los últimos 30 años la estructura ocupacional se vio radicalmente transformada.

\footnotetext{
* Para apreciar el cuadro completo véaseTorche y Wormald (2004: 15). Se debe dejar en claro que los datos aquí presentados nos muestran los porcentajes de los sectores medios asalariados e independientes en relación al total de la población económicamente activa, y no considerando a los sectores medios como el $100 \%$ de los casos (tal como se hace en el cuadro 1).
} 
Esto marcó de modo profundo la configuración de los sectores medios en lo que se refiere a su relación con el Estado, a su composición salarial, a su composición social interna y, en consecuencia, a la mayor capacidad de acción política fundada en torno a intereses generalizables que estos sectores tenían en la época del Estado de compromiso (si lo comparamos con la casi nula capacidad que tuvieron en el periodo dictatorial y que tienen en el actual régimen democrático).

En efecto, la jibarización de la función productiva del Estado implicó, como ya se dijo, un proceso de creciente privatización de los sectores medios que modificó fuertemente la relación con su antiguo «patrón», el Estado. Esta situación vino a tranfformar de sobremanera lo que podíamos entender hasta principios de los 70 como «clase media» (si se le quiere dar ese apelativo a dichos sectores, tal como comúnmente se ha hecho). Esto, en la medida en que si se denomina «clase» a aquél sector social que en una formación social concreta, además de compartir posiciones similares en la esfera productiva tiene también una posición determinada dentro de lo que podríamos llamar «ucha política de clases", como consecuencia de ello debemos asimismo considerar que una clase tiene, por definición, la capacidad de articularse de al gún modo u otro en torno a un proyecto político clasista que se exprese dentro de la estructura política (Poulantzas, 1988).

La importancia de este hecho radica en que si bien estosfenómenos no eran experimentados en su totalidad por los sectores medios-puesto que difícilmente puede afirmarse que existía homogeneidad de sus miembros en lo referido a las posiciones ocupadas por ellos en la esfera productiva, ni tampoco se puede apreciar que existía un proyecto político «de clase» dirigido por dichos sectores, sí se presentaban con más claridad en el período del Estado de Compromiso. Ejemplo de esto era la unificación de ellos bajo el «discurso mesocrático» y la existencia de posibilidades estructurales que les permitían entablar colectivamente las demandas a su máximo referente político e ideológico, el Estado, todo lo cual generaba pautas de acción que les permitían intervenir en lo político de modo comunitario, algo totalmente ausente en la actualidad.

En este sentido, se ha intentado demostrar que la privatización de los sectores medios implicó fenómenos tales como una creciente diferenciación (salarial y social) en su interior, lo que trajo consigo una imposibilidad estructural de ejercer una acción política en torno a intereses generales. D e igual modo, implicó que, debido a la estructura flexible de los empleos en este sector, se modificaran los patrones de movilidad social, primando, como ya se dijo, los criterios individuales de ascenso social por sobre la politización de demandas colectivas llevadas a cabo típicamente por los grupos profesionales. De ahí que, por más que la actual estructura ocupacional cuente con amplios sectores medios que se encuentran bajo formas asalariadas de trabajo - fenómeno que ha sido muchas veces considerado como un indicador de la organicidad de la estructura social (León y M artínez, 2001) - , el sustrato clasista que impera en las acciones de estos sectores es nulo en la medida en que no existen posibilidades que permitan la existencia de patrones políticos y normativos colectivos. 
Así pues, si al aumento de los patrones de movilidad individual se suma una cierta «estabilización» de los sectores independientes, (los cuales si bien disminuyeron cuantitativamente en la década de los 80, no por eso dejaron de ser un sector importante en la medida en que este estrato fue el que gozó, después de los 90, de niveles de ingresos más altos en relación al estrato de los asalariados) y un alejamiento de los sectores medios respecto de la clase obrera en lo que se refiere a ingresos, no es descabellado concluir que fueron en gran parte estos sectores los que legitimaron pasivamente, de un modo u otro, a partir de los beneficios económicos obtenidos, las transformaciones neoliberal es impulsadas por el régimen militar. Estas transformaciones, como se ha dicho, terminaron por desactivar las bases económicas estructurales que los sustentaban como un sector social que no sólo contaba con mucha mayor capacidad de acción política de la que tiene ahora, sino que también compartía patrones colectivos que lo sostenían normativamente.

\section{Integración social y reestructuración normativa. Bases sociales para la articulación de los sectores medios}

Los procesos de modernización llevados a cabo en $C$ hile desde la década de los ochenta han producido fuertes cambios en las orientaciones normativas de la sociedad 0 , en otras palabras, los procesos de diferenciación de la estructura productiva han llevado aparejado la aparición de nuevos grupos sociales, asocia dos a los nuevos sectores productivos, que portan una identidad nueva y que ponen en encrucijada a las categorías sociales clásicas y su identidad alcanzada en torno al Estado de Compromiso.

La integración social la entendemos como el desarrollo de anclajes normativos, mediante los cuales los procesos de modernización se vuelven reflexivos para los actoresque lo hicieron posible. ${ }^{25}$ En términos históricos, el desarrollismo asociado al Estado de Compromiso generó lazos normativos con los distintos sectores sociales que le daban vida, en la medida que éstos no solamente eran incorporados como meros beneficiarios del crecimiento económico sino también como agentes activos en la definición del modelo de desarrollo. ${ }^{26}$

Las transformaciones y reformas que la dictadura militar impulsó como conformadores de un nuevo o distinto tipo social pusieron en tela de juicio los principales mecanismos de integración social que el antiguo Estado de Compromiso había utilizado para anclarse en el saber cultural (práctico-moral) compartido por la sociedad en su conjunto; de esta manera, en principio, asistiríamos a una descomposición del tejido social presente en el Estado de Compromiso por los procesos de modernización, sin embargo, esto no quiere decir que desaparezcan completamente dichos mecanismos, sino que se readecuan o transforman.

${ }^{25}$ Sobre el concepto de integración social utilizado, véase H abermas (2002).

${ }^{26}$ Pese a ello, resulta difícil hablar de un proyecto hegemónico de clase al interior del Estado sino más bien de una alianza precaria entre distintas fracciones de clase. 
Así, parece absolutamente necesario indagar cómo funcionan los antiguos mecanismos de integración social y qué nuevos mecanismos aparecen asociados a este nuevo proceso modernizador en que el mercado cobra una gran centralidad, desplazando al Estado como eje directriz del desarrollo económico y la producción de identidad.

En términos habermasianos, la pregunta que orientaría esta sección es cómo los procesos de modernización impulsados por la dictadura militar han desintegrado los plexos normativos que permitían legitimar el sistema de dominación que imperaba durante el Estado de Compromiso y de qué forma este proceso de modernización genera nuevas formas de integración, que permitan la inclusión de los nuevos sectores sociales asociados al nuevo sistema productivo, entre los cuales obviamente cuentan los sectores medios, que jugaron un papel clave en el anterior modelo. Es de importancia destacar, que estas posibles nuevas formas de integración no sólo son entendidas en términos económicos sino principalmente como fuentes productoras de identidad y normatividad que cohesionen a losindividuos en torno a las condiciones objetivas que les dan origen.

La reconstitución de estos plexos normativos como base para la conformación de un grupo social homogéneo debe ser entendida como la formación de un nuevo vínculo comunitario. A esto hacemos alusión a lo que comprendía Weber por comunidad, a saber: «una relación social cuando y en la medida que la acción social [...] se inspira en el sentimiento subjetivo»(Weber, 1962: 33), es decir, cuando los vínculos que unen al individuo al grupo no son de carácter racional con arreglo a fines sino en el cual el individuo se siente parte de la totalidad, en una suerte de identificación con los valores que esa totalidad alberga, a lo cual Durkheim Ilamaría «conciencia colectiva». Así, una normatividad que se base en el individualismo no constituiría un avance en la conformación de un grupo social sino un retroceso en la conformación de la comunidad como un sentimiento de pertenencia a la totalidad.

Los mecanismos de integración que se podían identificar en el Estado de Compromiso y que evaluaremos en relación al nuevo sistema de dominación son los siguientes: trabajo, educación y consumo.

\section{Trabajo}

La centralidad del trabajo como eje constitutivo de las clases sociales, en cuanto a su configuración objetiva y sus formas de representarlas como significaciones sociales, estuvo asociada desde un comienzo a la modernidad como proceso histórico de reflexivización y racionalización de los vínculos sociales. El sustento material que fundamentaba este ideario en torno al trabajo estaba referido a la predominancia del sector industrial dentro de la economía mundial y nacional, basada en la existencia de un Estado fuerte que dirigía la economía. Este Estado no sólo se constituía como planificador económico sino también como plataforma de negociación de los distintos intereses que expresaban las clases sociales. En C hile, este Estado, al igual que en el resto deA mérica Latina, no sólo constituía esta plataforma de negociación de demandas sino también uno de los 
actores principales que dirigían el proceso de formación de las distintas clases o fracciones de clase que lo componían. La satiffacción de los distintos intereses que expresaban las clases por parte del Estado se basaba en su capacidad de producir recursos mediante los procesos de industrialización sustitutiva de importaciones que este mismo impulsaba.

En el caso de los sectores medios, este Estado subsidiario cobraba una particular importancia, pues no constituía solamente el espacio político de su expresión sino, como vimos, también el espacio estructural en el cual encontraba su lugar de trabajo y pertenencia social. La amplitud del Estado, en cuanto a sus funciones, exigía una amplia burocracia estatal, lo que constituyó, en términos clásicos, a los sectores medios. La importancia de esto no es solamente económica, como fuente de empleo, sino también normativa, en la medida que el principal referente identitario de estos sectores era el Estado o, más amplio, la identidad estatal nacional. Los sectores medios encontraban, de este modo, en el Estado su principal empleador y su principal referente normativo, en torno al cual orientaba sus prácticas políticas.

U n aspecto que es de vital importancia para subrayar el papel del Estado con respecto a los sectores medios es el carácter colectivista que inspiraba el ejercicio de las políticas públicas en $\mathrm{C}$ hile. Esto es particularmente sensible, en el sentido que las políticas de integración no consistían solamente en repartición de beneficios individuales sino también una articulación con los intereses generalizables que los grupos sociales, mediante acciones colectivas, negociaban al interior del Estado. Es, de este modo, como el Estado pretendía articular democracia política, incluyendo a los distintos sectores sociales, organizados mediante los partidos, en la toma de decisiones al interior de su seno y democracia social, entendida como la satiffacción de demandas por mejoramiento de las condiciones de vida.

Es este intento de articulación de democracia política (participación) y democracia social (incorporación de demandas) lo que estalla a principios de la década del setenta y que desemboca en la dictadura militar. La recomposición capitalista y reorganización social que impulsó la dictadura, que describimos anteriormente, minó la centralidad del trabajo en la conformación de identida des bajo el concepto de clase social, en la medida que los procesos de flexibilización laboral trajeron consigo, la desprotección y la inestabilidad laboral, ${ }^{28}$ evidenciables en el gran número de trabajos sin contrato $(23,2 \%)$ así como también en el alto grado de finiquitos de trabajos con contrato indefinido, supuestamente de más larga duración que los con contrato definido.

Esta flexibilización laboral fue acompañada por los procesos de desindustrialización y terciarización de la economía, cosa que, como vimos, es importantísima para los sectores medios, pues trajo consigo una amplia reducción de la burocracia estatal y, con ello, la pérdida de su principal empleador, con lo que tuvo que trasladarse al sector privado, asumiendo las condiciones de precarización mencionadas.

${ }^{28}$ Para ver detalladamente estos puntos, véase A guilar (2004). 
Según el informe sobre desarrollo humano del PN U D del año 2002 «la nueva desigualdad social, más allá de la distribución del ingreso, reside en la desigualdad frente a la precarización del empleo»(PN U D , 2002); esto dice relación con que los individuos deben enfrentar, junto a sus competencias para desarrollar el trabajo, condiciones desiguales de protección social aún cuando tengan competencias similares con otros individuos. La principal función del Estado en el Estado de C ompromiso, recalca el informe, no era la redistribución del ingreso sino la protección social frente al empleo, sobretodo en el caso de los sectores medios, cosa que ahora debe ser asumida de manera individual. A sí, la percepción de los ciudadanos en torno al trabajo actualmente, se refiere a entenderlo como un instrumento de adquisición de dinero para consumir y no como forma de autorrealización, cosa que se mantendría en los sectores altos, que no enfrentan las condiciones de precariedad laboral.

La reducción del aparato del Estado nos permite comprender que la matriz identidad-nación sustentada en la relación que sostenía el Estado como empleador con los sectores medios ha desaparecido. En otras palabras, su principal referente normativo ya no existe y, por tanto, el tejido social construido en su derredor ha sido fragmentado. Los procesos de reforma laboral que acompañaron a la liberalización de la economía durante la dictadura y afianzada durante las nuevas democracias ha llevado a una creciente individualización de las experiencias sociales, en la medida que los riesgos de la movilidad laboral no son asumidos por el Estado sino que dependen del individuo o, en última instancia, de los movimientos fluctuantes del mercado.

Como vemos, la reorganización del sistema de trabajo no nos lleva a pensar una nueva forma de integración social, en el sentido que estamos trabajando como integración económica y producción de normatividad, sino más bien un repliegue del individuo que no se identifica con el trabajo que realiza, sino que lo considera como medio para la satisfacción de otras necesidades; la pérdida de identidad que la reducción estatal produjo en los sectores medios parece ser algo irreparable desde el punto de vista del trabajo. Intentaremosindagar en las otras formas de integración para ver si asistimos a la recomposición del tejido social fragmentado, que los procesos modernizadores produjeron, cuestión que consideramos mínima para hablar de una clase media en términos homogéneos.

\section{Educación}

El acceso a educación fue una de las principales demandas a las cuales las distintas clases sociales, especialmente los sectores medios, apostaban, mediante su apoyo e inclusión al pacto social que subyacía en el Estado de Compromiso. El acceso a educación se veía como uno de los principales mecanismos de integración y movilidad social, en la medida que permitía a los sujetos adoptar competencias profesionales que le aseguraran su incorporación al Estado como burocracia o como mano de obra especializada en las labores propias de la industria. La educación era vista como una forma de paliar las desigualdades que a nivel de la estructura económica se producían, logrando desviar en términos positivos la trayectoria social del individuo como perteneciente a una clase social. 
En este sentido, la reforma de la educación superior de 1967 responde a las necesidades de cambio que experimentaba la sociedad desarrollista en su impulso modernizador, ${ }^{30}$ en la medida que las distintas fracciones de clase que conformaban el pacto social (burguesía nacional, sectores obrerosurbanos organizados, campesinos y sectores medios) presionaban por su incorporación tanto al proyecto modernizante como a sus beneficios. En este sentido, la ampliación en la oferta de matrículas universitarias y la apertura de carreras técnicas en la U niversidad T écnica del Estado respondía a necesidades sociales que el mismo proyecto de desarrollo contribuía a formar.

Con las reformas neoliberales de la década de los ochenta, asistimos a una serie de cambios en torno a todos los niveles de la educación. En primer lugar, se munici palizan los colegios públicos desligándolos de la tarea estatal, esto tuvo diversas consecuencias dentro de las cuales destacan la baja en la calidad de los colegios, fruto de la desregulación en que el sistema se ve involucrado. En segundo lugar, surgen gran cantidad de colegios privados que no hacen más que resaltar por negación la mala calidad de la educación a nivel básico y medio de los primeros. Si bien no se puede olvidar que se amplió la cobertura de los servicios de educación básica y media, las condiciones de pobreza y exclusión que anteceden a la elección de educación pública y privada es enfatizada; esto queda de manifiesto en los problemas de deserción y repitencia que afectan en mayor medida a los sectores de menos ingresos, no así a los sectores altos. A sí, la diferencia entre la educación pública y privada se acrecienta, reproduciendo las desigualdades que pretendiera erradicar, y no logrando la movilidad social esperada.

En cuanto al sistema de educación superior ocurre un fenómeno similar. Con la aparición de universidades privadas, se produjo un proceso de gran ampliación de las matrículas y, por tanto, de un mayor ingreso de personas al sistema educativo, sin embargo, se da un fenómeno inverso al de la educación básica y media, en la medida que las universidades públicas siguen teniendo la mayor excelencia académica, aún a costa de autofinanciarse e incorporar mecanismos de mercado en la oferta de vacantes en las distintas carreras. Pese a que las universidades públicas sean cualitativamente mejores, se observa un mayor ingreso de alumnos del sector privado a éstas, ligado a los sectores más altos de la sociedad, reproduciendo la desigualdad originaria y derribando el mito de la educación superior como garante de movilidad social.

En síntesis, podemos decir que, si bien la ampliación de matrículas y el florecimiento de las universidades privadas han aumentado la cobertura en Educación Superior, esto no ha sido fruto de una necesidad social sino más bien de una desregulación de los procesos educativos que no van dirigidos por el Estado sino por el mercado. Como vemos, tampoco en esta forma de integración podemos apreciar la recomposición de un tejido normativo que permita anclar los procesos de modernización sino que refleja su creciente distancia.

30 Para profundizar en este tema, véase Fleet (2004). 


\section{Consumo}

El consumo representa una forma de integración de segundo orden, en la medida en que está supeditado a la creación de empleos y al éxito pecuniario. El consumo, en un sentido amplio, no es nuevo, sin embargo, a partir de la generación incipiente de una sociedad de consumo en América Latina y, particularmente, en $C$ hile, asume diferentes rasgos que lo hacen cobrar una especial relevancia como mecanismo de integración simbólica, desplazando al trabajo y la educación como mecanismos clásicos de integración.

El consumo no es nuevo, en la medida que, como mencionamos anteriormente, las demandas por participación política que desarrollaban las clases sociales o sus fracciones organizadas siempre fue acompañado por una demanda de satisfacción de sus necesidades materiales, lo que constituía los procesos de democratización social. La clave para entender este tipo de consumo la podemos encontrar precisamente en el concepto de necesidad, que bajo un concepto de clase, nos liga directamente al paradigma de la producción, es decir, el motor de la producción de mercancías tiene como eje directriz la satisfacción de las necesidades de las clases, como sujetos de la producción, que se configuran en relaciones sociales de intercambio. Así, las necesidades que enarbolaban las clases como prioritarias tenían relación con el acceso privilegiado a los sistemas de salud, vivienda y educación, que sólo se conseguían mediante una incorporación política a la toma de decisiones estatales en la evaluación de criterios redistributivos.

Este papel redistributivo y de satiffacción de necesidades estaba asignado al Estado durante el periodo del Estado de Compromiso, ya que, como vimos, contaba con altas cantidades de recursos, fruto del desarrollo industrial, y tenía como principal función la protección social. Sin embargo, este consumo era diferenciado, en la medida que las clases altas tenían un acceso privilegiado, sobre todo en relación a la vivienda y la educación; lo que intentaba el Estado, de este modo, era generar mecanismos redistributivos que permitieran paliar la desigualdad expresada en el acceso diferenciado a los bienes de consumo necesarios para la subsistencia. Es de importancia destacar, que estos bienes de consumo en su mayoría eran de carácter público, es decir, asociado al Estado; de esta manera, se reforzaba la identidad asociada al Estado nacional ya no sólo como empleador sino también como productor de los bienes de consumo básicos, es decir, como protector social.

La desarticulación del Estado de Compromiso durante la dictadura llevó, como vimos, a la privatización de los principales servicios sociales, en los que, junto a los mencionados, destacan los fondos de pensiones. A sí, junto a la educación pública en Enseñanza básica y media se comenzó a desarrollar un sistema privado, que satisfacía la misma necesidad pero orientado por mecanismos de mercado de configuración de la oferta y no obedeciendo a una necesidad social; a su vez, la municipalización de los colegios públicos desligó definitivamente a éstos del alero del Estado, minando su capacidad regulatoria y destruyendo los principales lazos normativos que ligaban las políticas educacionales al desarrollo de la sociedad. 
EI acceso a la vivienda se empieza a generar en torno al desarrollo de subsidios habitacionales que premian la capacidad de ahorro individual y de constancia en el pago de las mensualidades.Vemos otro mecanismo de mercado que se introduce en el desarrollo de políticas públicas, lo que desliga, cada vez más, la relación entre política formal (institucionalidad democrática) y democratización social (satisfacción de intereses). Por su parte, el sistema de salud también se privatiza, lo que ensancha, de manera creciente, la barrera social que separa a la población que accede a un sistema público, de baja calidad, y los sectores altos que acceden al sistema privado, de alta calidad. En este sentido, los servicios públicos se constituyen como espacio de reproducción de la desigualdad y no como sus neutralizadores. El concepto de necesidad deja de regir la oferta de servicios públicos y es la eficiencia económica el criterio que impera, cooptando desde el mercado las distintas esferas de la sociedad.

Así, vemos que la privatización del acceso a la vivienda, la salud y la educación trasladan una responsabilidad social, incluso en los términos más funcionalistas, de las necesidades básicas para el mantenimiento de los integrantes del sistema social, a los propios individuos que, a la vez que se enfrentan con condiciones de incertidumbre en su ámbito laboral, deben preocuparse por superar individualmente condiciones de exclusión en el acceso a los bienes de consumo necesarios para la sobrevivencia. En otras palabras, estamos asistiendo al paso de una estatización de las demandas clasistas a una mercantilización de las demandas individuales.

Sin embargo, el concepto de consumo que opera hoy en día, y que es particularmente relevante para la constitución de los sectores medios, es el asociado a la idea de signo. La lógica que opera en la circulación de las mercancías ya no coincide con las necesidades ni el paradigma de la producción sino con la lógica de la distinción, que opera a nivel de los objetos signo (como un sistema de los objetos $^{31}$ ), dejando fuera al sujeto y sus necesidades y que lo constriñe estructuralmente. Este tipo de consumo de objetos signo (objetos que distinguen a losindividuos con respecto a sus semejantes) cobra una especial relevancia como productor de significación, estimulando a los procesos de individuación que en una sociedad homogénea culturalmente parece sumamente necesario.

La integración social mediante el consumo plantea un desafío previo que debe enfrentar el Chile actual, en el sentido que el crecimiento económico, dada la inserción al mercado mundial globalizado, debería aumentar la oferta de empleo y, por tanto, los sujetos percibidores de salario podrían acceder al mercado. Esto, sin embargo, no parece ser tan así, en la medida que, si bien en un comienzo el impacto modernizador de las economías latinoamericanas logró aumentar la oferta de empleo, actualmente los procesos de modernización interna regulados por el mercado no son capaces por sí solos de integrar, a un ritmo de alta productividad, a mayores grupos sociales al proceso de desarrollo, generando una marginalidad estructural así como también un acceso diferenciado a la estructura de oportunidades que ofrece el mercado.

${ }^{31}$ Para un análisis teórico de este sistema de los objetos, véase Baudrillard (1999). 
Por otro lado, el patrón de integración basado en el consumo está generalmente regulado por la demanda de los sectores altos de la clase media y por sectores al tos propiamente tal, lo que genera pautas de exclusión social inherentes a la oferta selectiva desarrollada en el mercado. Así, el acceso privilegiado a los bienes durables está destinado a sectores beneficiados de antemano con el desarrollo neoliberal, mientras que los sectores populares no tienen acceso a este tipo de bienes ni a bienes de consumo directo de alta calidad.

Las oportunidades de consumo para los sectores medios (excepto para sus sectores altos) depende de sus posibilidades de acceso a crédito. El crédito (dinero ficticio) es el mecanismo que habría generado la sociedad de consumo para desligar esta práctica del paradigma de las necesidades y la producción, en la medida que el individuo puede consumir más de los ingresos económicos que percibe, tornando irrelevante la distribución del ingreso a la hora de consumir. Sin embargo, la identificación del individuo como consumidor tiene negativos efectos en torno a su seguridad, ya que su posibilidad de consumir y de, por tanto, reconocerse como parte de la sociedad está en relación a su capacidad de acceder a crédito, lo que a su vez es dependiente del grado de aceleración en el crecimiento del sistema financiero. El sobreendeudamiento también constituye una fuente de inseguridad y afecta principalmente a las clases medias; el informe del PN U D de 1998 ofrece cifras expresivas al respecto: $\ll \mathbb{E} I$ sobreendeudamiento ocurre especialmente en la clase media (C2) que destina en promedio al rededor del 39\% de sus ingresos al pago de créditos de consumo»(PN U D , 1998: 188).

A sistimos, de esta manera, a un desplazamiento de la función normativa del trabajo al consumo referido a la relación que establece el individuo con el vínculo social que lo une y, a la vez, diferencia de los demás individuos, proyectando una imagen individualizada de la relación social significante y la totalidad social que lo alberga.

El consumo de signos y símbolos pasa a constituirse como un fin en sí mismo, desligado de su significación material. C uando una persona que pertenece a un grupo medio compra un auto, no está referido el acto a la necesidad del individuo de tener un auto sino de acceder simbólicamente a capas sociales elevadas distanciándose cada vez más de los asalariados más bajos. N otamos, en ese sentido, un fuerte contenido aspiracional del consumo que permite hacer «desaparecer» las barreras sociales que lo separan de sus semejantes, a medida que se distingue. Para los fines de este artículo, parece interesante incorporar la tipología del consumidor que desarrolla el informe del PNUD del año 2002 (PNUD, 2002: 100-1).

Según el informe del PNUD, se pueden distinguir cuatro tipos de consumidores, a saber: 1) el consumidos necesitado, que está guiado por la satisfacción de carencias, teniendo una fuerte relación con el nivel socioeconómico. Conforma el consumo que más desarrolla la población (42\%); 2) el consumidor de bienestar, que constituye el tipo más pequeño (13\%) y se caracteriza por familias carenciadas que, a través del ahorro, logran obtener ciertos bienes de mayor costo como televisores o refrigeradores; 3) el consumidor existencial, que está asociado a la falta de identidad de los sectores medios que buscan en el acto de 
consumir una forma de diferenciación con sus pares, constituyéndose el tener en una forma de ser. Está representado demográficamente por el $19 \%$ de la población; 4) el consumidor modelo, el cual constituye el ideal del consumidor al que apela la sociedad de consumo y que se gratifica en su práctica, desarrollando formas de estetización de su vida cotidiana, logrando su autorrealización a través del consumo. R epresenta el $26 \%$ de la población.

Estos distintos tipos de consumidores nos sugieren ciertas reflexiones, a sa ber: el cambio cultural que traslada el eje de la ética del trabajo a la estética del consumo no parece ser tan claro, en la medida que el $55 \%$ de la población es un consumidor necesitado y/ o de bienestar, es decir, que corresponde a los sectores populares y sectores medios bajos que no orientan su práctica mediante el consumo. Sin embargo, el $45 \%$ restante sí orienta su práctica por el consumo, pero presentando distinciones, a saber: el tercer tipo de consumidor se integra a la sociedad de manera más aspiracional que real, es decir, su distinción social sólo se da a nivel simbólico, impidiendo la realización de la aspiración de movilidad social. Sólo el último grupo que corresponde a los sectores al tos es el que guía realmente sus prácticas por el consumo y se siente gratificado en su realización.

Así, el consumo como de eje de integración queda puesto en duda, en la medida que reproduce las desigualdades que se dan a nivel del ingreso, siendo el sistema crediticio un paliativo a corto plazo, y dependiente de las fluctuaciones del mercado. Por otra parte, respondiendo la pregunta que dirigimos en la sección sobre el trabajo acerca de la recomposición de tejidos normativos que el consumo como mecanismo de integración social pudiera generar, tampoco parece ser tan claro, en el sentido que estimula procesos de diferenciación a nivel individual, impidiendo la reconstitución a nivel de grupos sociales; además que, como vimos, la función portadora de identidad del consumo queda replegada fundamentalmente a los sectores altos, los cuales presentan una mayor grado de homogeneización cultural y capital social.

\section{Consideraciones finales. Los sectores medios y la esfera política}

A partir del diagnóstico y las reflexiones aquí apuntadas, es evidente la constatación de un profundo cambio tanto en la composición de los sectores medios como en su identidad y patrones de comportamiento, todo esto al amparo de los procesos de modernización de sello neoliberal.

En efecto, como hemos intentado precisar, las transformaciones estructurales llevadas a cabo durante la dictadura instalan una nueva lógica o racionalidad que orienta a los procesos de modernización, a partir de los cuales se va articulando un modelo societal signado por la construcción hegemónica del neoliberalismo. Es dentro de este nuevo contexto social, entonces, que los sectores medios han experimentado profundas alteraciones en sus bases constitutivas y sus mecanismos de integración social.

A hora bien, tal como apuntábamos al comienzo, esta serie de tranformaciones estructurales y su consiguiente impacto en los sectores medios, no pueden ser leídas al margen de los reordenamientos sociopolíticosque se han producido en $C$ hile durante las últimas décadas, vale decir, al cambio operado en las rela- 
ciones entre los sujetos y fuerzas sociales que conducen y dan dinamismo al estilo de desarrollo vigente. En este sentido, se trata fundamentalmente de la desarticulación del pacto o alianza social que sustentaba al Estado de Compromiso y al proyecto desarrollista, y su reemplazo por un nuevo bloque histórico, liderado por los sectores vinculados al capital financiero transnacional, que ha logrado instalar sus orientaciones como hegemónicas en las configuraciones estructurales y las dinámicas de la sociedad chilena.

Son estos sectores, entonces, los que han conducido los procesos de instalación y consolidación del nuevo estilo de desarrollo, el cual, sin embargo, ha experimentado algunas inflexiones durante el último tiempo que son pertinentes de apuntar por la relevancia que tienen en relación a los sectores medios. Particularmente, en el debate político y académico reciente, se ha tendido a constatar que los procesos de despliegue productivo y crecimiento económico no han logrado cuajar en niveles adecuados de integración social o participa ción política, que sean capaces, al menos, de establecer el trasfondo de legitimidad necesario para el desenvolvimiento estable del modelo y sus lógicas. ${ }^{34}$

Es dentro de esta constatación que se ha instal ado crecientemente un discurso dirigido hacia los sectores medios, en donde éstos aparecen llamadoso interpelados a representar un rol activo en la conducción y la recepción de beneficios del modelo de desarrollo. Aquel discurso pareciese fundamentarse en dos ejes 0 consideraciones. Por una parte, en el ya descrito proceso de instalación del mercado como mecanismos de coordinación y referente simbólico primordial, enfatizando desde ahí las prácticas del consumo y el emprendimiento como instancias privilegiadas para la consecución del bienestar y la participación social.Y por otra, en la idea de una incorporación activa de los sectores medios en el pacto social que conduce el estilo de desarrollo vigente, o más bien, de una reapertura de los espacios de participación política - fundamentalmente desde el discurso que apela a la participación ciudadana- con tal de que estos sectores logren una mayor consideración en la conducción de las dinámicas de desenvolvimiento del modelo. En suma, asistimos a una interpelación discursiva desde la esfera política ${ }^{35}$ hacia los sectores medios, en términos de la posibilidad que radicaría en éstos de asumir un rol preponderante, 0 al menos incidente, en las configuraciones estructurales y la dirección del estilo de desarrollo neoliberal.

${ }^{34} \mathrm{~N}$ os referimos, por ejemplo, a los conceptos de «desarrollo humano», «desarrollo comprensivo», «desarrollo integral», etc., que se han empleado con frecuencia últimamente para caracterizar los desafíos que por sí solo el crecimiento económico no ha logrado cumplir. También se puede considerar expresivo de esto el denominado «viraje hacia la izquierda»o «avance del progresismo» que se ha experimentado en varios países de A mérica Latina.

35 U tilizamosel término esfera políticano como un símil del aparato político-administrativo o el sistema de representación, sino - incluyendo aquello- como el espacio social en donde se disputan y articulan la centralidad de las correlaciones de fuerza que determinan el sentido que asumen las estructuras y dinámicas sociales en una momento histórico determinado. Precisamente, como parte de la construcción hegemónica de aquel sentido estructurador podemos identificar la producción de determinados discursos e interpelaciones discursivas. 
Sin embargo, es preciso destacar que esta interpelación discursiva que el actual modelo neoliberal realiza hacia los sectores medios choca con fronteras estructurales que impiden que estos sean sus «conductores». En efecto, y tal como intentamos demostrar, a partir de las trasformaciones neoliberales se produjeron una serie de fenómenos que desestructuraron las bases objetivas a partir de las cuales los sectores medios se configuraban como un sector social con cierta capacidad de acción política.

Entre esas tranforormaciones se pueden mencionar, por ejemplo, las acaecidas en el ámbito económico (siendo de especial importancia los cambios en la estructura laboral) y en el político (jugando un rol fundamental la nueva forma que tomó la relación entre el Estado y la sociedad civil, así como la nueva orientación de los partidos políticos). Todo esto vino a configurar nuevos patrones normativos, en tanto se vieron alterados factores tales como el trabajo (que de ser un fuerte generador de identidades sociales, se volvió precario e inestable, convirtiéndose en un nuevo factor de heterogeneización social), los cuales eran fundamentales para la conformación de mecanismos de integración social basados en una cierta concordancia entre las prácticas individuales y las acciones colectivas.

En este sentido, cobra una relevancia fundamental analizar fenómenos como el consumo, actividad que - tal como se intentó demostrar - no es capaz de generar, debido a la naturaleza individual ista de sus prácticas, anclajes normativos en una sociedad. Este fenómeno se aprecia con claridad en los sectores medios, los cuales ven en esta práctica una variable más de inseguridad, en la medida que el medio de acceder a él esa través de actividades maximizadoras de beneficios sustentadas en el crédito, o sea, en el endeudamiento. En este contexto, se demostró que no es de extrañar que sólo sean los sectores al tos los que se sientan, en cierto modo, seguros y realizados e través del consumo, puesto que al tener las reales posibilidades de consumir, no experimentan las inseguridades que conlleva el realizar dicha práctica por medio de mecanismo como el crédito (algo propio de los sectores medios). A partir de esto, queda claro que la masificación de fenómenos como el consumo más que menguar las diferencias provenientes de los ingresos tienden a reproducirlas, algo similar a lo que se podría evidenciar en la actualidad en el terreno de la educación (la cual, por muy masiva que sea, termina por reproducir dichas diferencias salariales).

Así, pues, parece claro que la extensión de prácticas como la del consumo no logran configurar patrones identitarios y normativos que sustenten a los sectoresmedios en términos de capacidad de acción colectiva e incidencia en la esfera política que, al menos discursivamente, debiesen tener en el actual modelo de desarrollo. M ás aún, si a esto le sumamos la desestructuración de los factores económico-políticos que aseguraban cierta aglutinación de dichos sectores medios, debemos concluir que efectivamente existe una incapacidad estructural de éstos para constituirse en algo similar a una clase, 0 al menos, en un sector social con cierta capacidad de acción colectiva configurada en torno a intereses generales.

Todo esto pareciese condenarlos a ser una suerte de legitimadores pasivos de 
un modelo de desarrollo que, si bien muchas veces les permite acceder a beneficios económicos, imposibilita toda su capacidad de acción colectiva e incidencia política y, por tanto, los obliga a ser meros receptores de transformaciones que, más allá del discurso hegemónico, responden con claridad a los intereses y la conducción de otros sectores sociales.

\section{$R$ eferencias}

A guilar, 0 mar. (2004). G lobalización, modelo de desarrollo y trabajo en Chile. $R$ evista $N$ émesis(Santiago, U niversidad de C hile), 4.

Baudrillard, Jean. (1999). El sistema de losobjetos. M éxico: Siglo XXI.

C ardoso, Fernando H . y Enzo Faletto. (2003). Dependenciay desarrollo en A mérica Latina. BuenosAires: Siglo XXI.

Fazio, H ugo. (2005). M apa de la extrema riqueza en Chile. Santiago: Lom.

Fleet, N icholas. (2004).Transformaciones sociales y educación superior en Chile. U n ensayo de interpretación sociológica. $R$ evista N émesis(Santiago, U niversidad de C hile), 4.

Garretón, M anuel A . (1997). La transformación de la acción colectiva en A mérica Latina. $R$ evista de laCEPAL, 76 .

Gramsci,Antonio. (1971). N otassobre M aquiavelo, sobre política y sobre el Estado moderno. M éxico: Juan Pablos editor.

H abermas, Jürgen. (1998). Problemas de legitimación en el capitalismo tardío. BuenosA ires. Amorrortu.

—. (2002). Teoría de la acción comunicativa. M adrid:Taurus.

$H$ achete, D ominique (2000). Privatizaciones: $R$ eformaestructural pero inconclusa En F. Larraín

y R .Vergara(editores), Latransformación económica de C hile.Santiago: Centro de Estudios Públicos.

PN U D. (1998). Informe de D esarrollo H umano: Lasparadojas de la modernización. Santiago.

- . (2002). Informe D esarrollo H umano: N osotrosloschilenos, un desafío cultural.Santiago.

León,Arturo y Javier M artínez. (2001). La estratificación social chilena haciafinesdel siglo XX. Santiago: C epal (Serie Políticas Sociales).

M artínez, Javier y EugenioT ironi. (1985). Las clases sociales en C hile. Cambio y estratifica ción, 1970-1980. Santiago: Ediciones Sur.

M ontero, C ecilia y Pablo M orris. (2001). El impacto de la globalización en los mercados laborales. Santiago: Prosur.

Poulantzas, N icos. (1988). Poder político y clases so ciales en el Estado capitalista. M éxico: Siglo XXI.

R uiz S., C arlos. (1993). C oncepciones de la democracia en la transición chilena. En Seis ensayossobre teoría de la democracia. Santiago:U niversidad AndrésB ello.

Torche, Florenciay Guillermo Wormald. (2004). Estratificación y movilidad social en Chile: entre la adscripción y el logro. Santiago: C epal (Serie de Políticas Sociales).

Weber, M ax. (1962). Economía y sociedad. M éxico: Fondo de C ultura E conómica. 